\title{
Cervical esophageal adenocarcinoma arising from heterotopic gastric mucosa, treated with endoscopic submucosal dissection
}

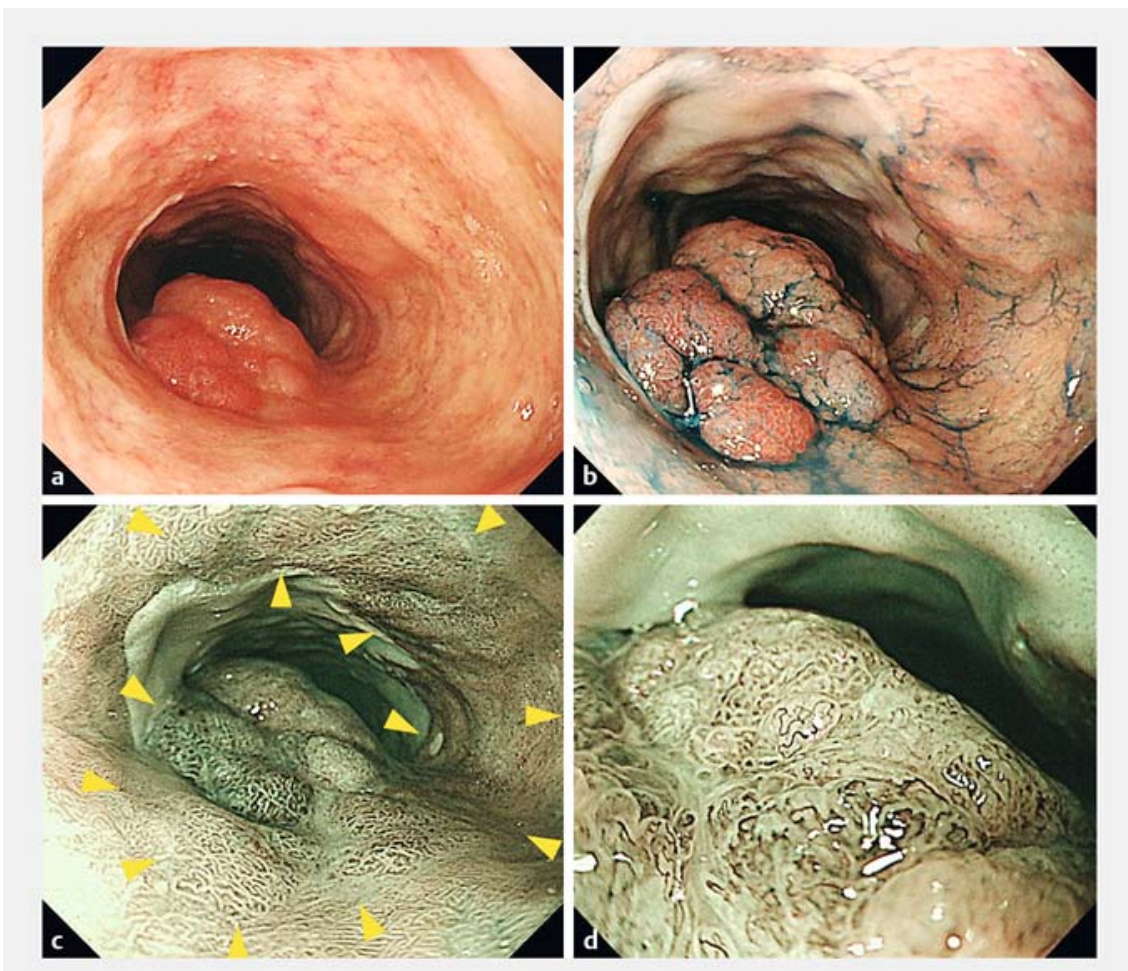

- Fig. 1 Cervical esophageal adenocarcinoma arising from heterotopic gastric mucosa (HGM). a Conventional endoscopy revealed circumferential HGM of the cervical esophagus and a 20 -mm protruding lesion in the posterior wall. b Indigo carmine spraying revealed a flat lesion in the reddish mucosa, but the demarcation line was unclear. c Narrow band imaging (NBI) revealed a clearly demarcated brownish area consistent with the reddish area (arrowheads). d Magnifying NBI revealed villous and glandular structures of various sizes and a dense distribution of abnormal capillaries.

Esophageal adenocarcinoma arising from heterotopic gastric mucosa (HGM) is extremely rare $[1,2]$. We describe a case of esophageal adenocarcinoma arising from HGM in the cervical esophagus that was treated with endoscopic submucosal dissection (ESD).

A 58-year-old man found to have an esophageal tumor on endoscopy was referred to our hospital for further examination and treatment. Conventional endoscopy revealed circumferential HGM of the cervical esophagus and a 20-mm protruding lesion in the posterior wall. Poorly defined reddish mucosa surrounded the protruding lesion ( $\mathbf{F i g . 1} \mathbf{a}$ ). Spraying with indigo carmine visualized the flat lesion in the reddish mucosa, but the demarcation line was unclear ( Fig.1b). Narrow-band imaging (NBI) revealed a clearly demarcated brownish area consistent with the reddish area at $18-21 \mathrm{~cm}$ from the upper incisors, with villous and glandular structures of various sizes and dense distribution of abnormal capillaries ( $\mathbf{F i g . 1} \mathbf{c}, \mathbf{d}$ ). Biopsy

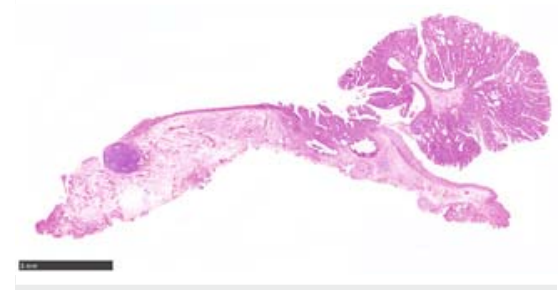

- Fig. 2 Histologically, tumor cells showed well-differentiated adenocarcinoma in the muscularis mucosa.

showed adenocarcinoma, with no evidence of deep submucosal invasion. Therefore, ESD was performed using a dual knife (KD-655L; Olympus, Tokyo, Japan) and an ITknife nano (KD-612; Olympus, Tokyo, Japan) ( Video 1). The resected specimen measured $51 \times 35 \mathrm{~mm}$ and contained a macroscopically measured $32 \times 27-\mathrm{mm}$ tumor surrounded by HGM. Histologically, the tumor cells showed well-differentiated adenocarcinoma in the muscularis mucosa (> Fig.2). Immunohistochemically, the tumor cells were positive for mucin (MUC) 2, MUC5AC, and MUC6.

The estimated incidence of HGM of the esophagus is $0.75 \%-11 \%$ based on endoscopic studies $[3,4]$. Primary adenocarcinoma arising from HMG is rare and several cases of mucosal cancer have been reported $[1,2,5]$. The macroscopic appearance was protruding or polypoid in most cases [5]; therefore, adenocarcinoma should be suspected when a protrusion is identified in HGM in the esophagus.

Endoscopy_UCTN_Code_TTT_1AO_2AG

Competing interests

None 


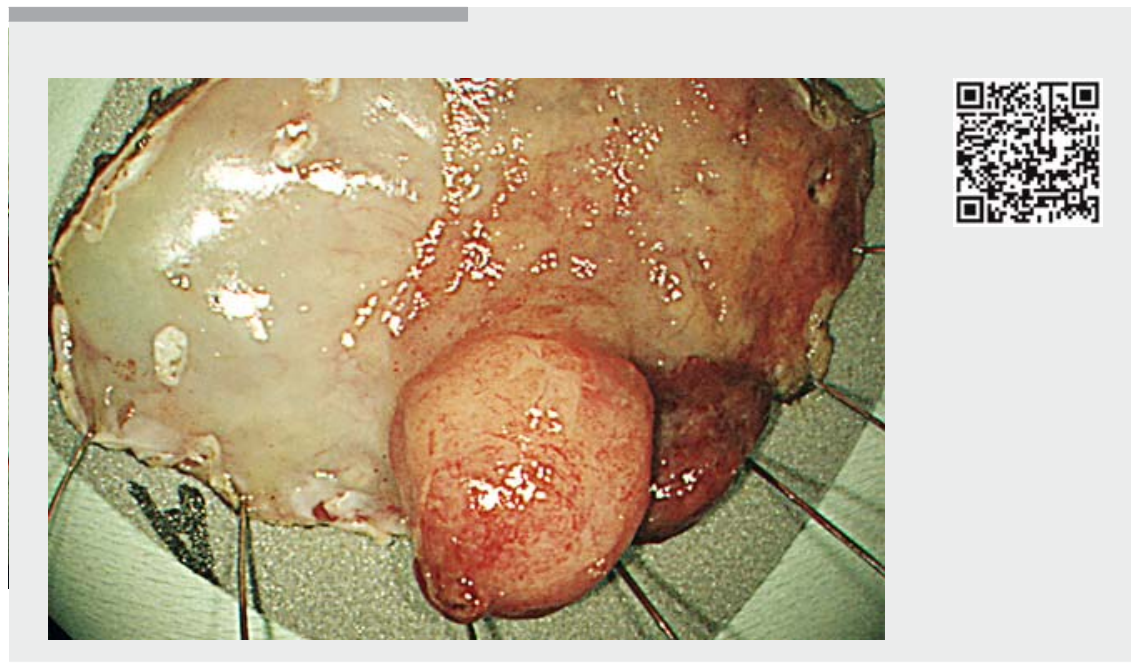

$\checkmark$ Video 1 Endoscopic submucosal dissection of cervical esophageal adenocarcinoma arising from heterotopic gastric mucosa.

The authors

Yasuhiro Oono ${ }^{1,2}$, Shinmura Kensuke', Yusuke Yoda $^{1}$, Keisuke Hori' ${ }^{1}$, Hiroaki Ikematsu' ${ }^{1}$, Tomonori Yano' ${ }^{1}$

1 Department of Gastroenterology and Endoscopy, National Cancer Center Hospital East, Chiba, Japan

2 Department of Internal Medicine, Tokyo Metropolitan Ebara Hospital, Tokyo, Japan

\section{Corresponding author}

\section{Yasuhiro Oono, MD}

Department of Gastroenterology and Endoscopy, National Cancer Center Hospital East, 6-5-1, Kashiwanoha, Kashiwa, Chiba 277-8577, Japan

Fax: +81-4-71346928

yohno@east.ncc.go.jp

\section{References}

[1] Noguchi T, Takeno S, Takahashi Y et al. Primary adenocarcinoma of the cervical esophagus arising from heterotopic gastric mucosa. J Gastroenterol 2001; 36: 704-709

[2] Yasar B, Tarcin O, Benek D et al. Intramucosal adenocarcinoma arising from ectopic gastric mucosa in the upper esophagus treated successfully with endoscopic mucosal resection. J Gastrointest Cancer 2014; 45 (Suppl. 01): $201-204$

[3] Weickert U, Wolf A, Schroder C et al. Frequency, histopathological findings, and clinical significance of cervical heterotopic gastric mucosa (gastric inlet patch): a prospective study in 300 patients. Dis Esophagus 2011; 24: 63-68

[4] Yu L, Yang Y, Cui L et al. Heterotopic gastric mucosa of the gastrointestinal tract: prevalence, histological features, and clinical characteristics. Scand J Gastroenterol 2014; 49: $138-144$
[5] Kadota T, Fujii S, Oono Y et al. Adenocarcinoma arising from heterotopic gastric mucosa in the cervical esophagus and upper thoracic esophagus: two case reports and literature review. Expert Rev Gastroenterol Hepatol 2016; 10: 405-414

\section{Bibliography}

DOI https://doi.org/10.1055/a-0767-6253

Published online: 23.11.2018

Endoscopy 2019; 51: E28-E29

(c) Georg Thieme Verlag KG

Stuttgart · New York

ISSN 0013-726X

\section{ENDOSCOPY E-VIDEOS}

https://eref.thieme.de/e-videos

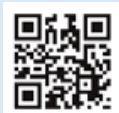
Endoscopy E-Videos is a free access online section, reporting on interesting cases and new techniques in gastroenterological endoscopy. All papers include a high quality video and all contributions are freely accessible online.

This section has its own submission website at https://mc.manuscriptcentral.com/e-videos 